\title{
IMPACT DAMAGE ASSESSMENT IN BIOCOMPOSITES BY MICRO-CT AND INNOVATIVE AIR-COUPLED DETECTION OF LASER-GENERATED ULTRASOUND
}

\author{
Balthasar Fischer ${ }^{1}$, Fabrizio Sarasini ${ }^{2 *}$, Jacopo Tirillò ${ }^{2}$, Fabienne Touchard ${ }^{3}$, Laurence Chocinski- \\ Arnault ${ }^{3}$, David Mellier ${ }^{3}$, Nils Panzer ${ }^{1}$, Ryan Sommerhuber ${ }^{1}$, Pietro Russo ${ }^{4}$, Ilaria Papa ${ }^{5}$, Valentina \\ Lopresto $^{5}$, Romain Ecault ${ }^{6}$ \\ ${ }^{1}$ XARION Laser Acoustics GmbH, Vienna, Austria \\ ${ }^{2}$ Department of Chemical Engineering Materials Environment, Sapienza-Università di Roma, \\ Roma, Italy \\ ${ }^{3}$ Pprime Institute, CNRS-ENSMA-Université de Poitiers, Department of Physics and Mechanics of \\ Materials - ENSMA, Futuroscope Cedex, France \\ ${ }^{4}$ Institute for Polymers, Composites and Biomaterials (IPCB), National Council of Research, \\ Pozzuoli, Naples, Italy \\ ${ }^{5}$ Department of Chemical, Materials and Production Engineering, University of Naples Federico II, \\ Naples, Italy \\ ${ }^{6}$ Airbus Operations S.A.S., Toulouse, France
}

\begin{abstract}
The increasing use of natural fibre composites in at least semi-structural applications along with a demand for a fast and accurate damage detection for quality purpose and in-service reliability promote a need for non-contact non-destructive testing techniques. To this purpose, ultrasound is probably one of the most widely used testing techniques but the need of a coupling fluid like water limits its use with natural fibre composites. In this work, a novel non-contact set-up based on laser excitation of ultrasound and detection with a broadband, air-coupled optical microphone is presented and tested on flax/PLA laminates. This material system has been characterized in terms of quasi-static mechanical properties and low velocity impact response. The outcomes of this study demonstrate the potential of this non-contact and nondestructive system for quality and damage inspection purposes of natural fibre composites.
\end{abstract}

Keywords: Polymer-matrix composites; Natural fibres; Low-velocity impact; Non-destructive testing; Micro-CT

\footnotetext{
* Corresponding author: Fabrizio Sarasini. Tel.: +39 0644585408; E-mail: fabrizio.sarasini@uniroma1.it
} 


\section{Introduction}

Composite materials have gained wide acceptance in a broad range of both low- and hightechnology engineering applications driven by several advantages including higher specific strength and stiffness, superior corrosion resistance as well as improved fatigue properties compared to metals. However, composite materials are inherently prone to defects that can be caused by imperfect manufacturing (embedded foreign objects, regions of excessive porosity, mistakes in ply orientation or layup sequence, ply waviness, and delamination) or can occur in-service, mainly related to low velocity impacts, leading to non-visual damage on the surface but significant internal damage [1].

As the use of composite increases, there is a greater need for non-destructive inspection procedures in both the manufacturing of the structures and in their subsequent in-service maintenance and repair. In particular, there is a strong need to develop testing techniques able to detect defects quickly and reliably, which has prompted the development of a number of methods and techniques over the years. The most promising techniques that meet these requirements and are commercially available include passive [2] and active [3] thermography, shearography and ultrasonic [4,5]. In this regard, ultrasonic inspection, due to its flexibility and ability to reveal internal defects such as delaminations or cracks, is probably one of the most widely used testing techniques, especially in the field of impact damage detection, which is generally recognized as one of the most severe threats to composite materials. However, current ultrasonic testing is conventionally performed using either liquid coupling (water, usually) or some type of gel or oil in contact-mode coupling. Alternatives involve the coupling of acoustic energy via a localised water jet. These conventional systems are typically slow, require significant setup time for highly contoured parts, and are generally not suitable for in-service inspections where access is limited to a single side. In addition, immersion of some composite materials may result in moisture absorption and subsequent loss of mechanical integrity, which is particularly important for composites reinforced with natural fibres. Natural fibre composites represent a family of composite materials that have been intensively investigated in the last two decades for benefits such as reductions in weight, cost, and $\mathrm{CO}_{2}$, less reliance on oil sources, and recyclability [6,7]. Their global market is forecast to grow at a CAGR of $8.2 \%$ from 2015 to 2020 , the major driver being the rise in demand for lightweight and environmentally sustainable composite materials in various applications, such as automotive, building and construction [8]. Despite this growing interest, the applications of such materials are still mainly confined to the non-structural field, due to several technical and scientific challenges that include the variable fibres' mechanical properties, a full understanding of their mechanical 
behaviour and damage modes, fibre/matrix interfacial adhesion, moisture repellence and flameretardant properties. For these composites to be used in structural components, it is important that the designers and manufacturers understand how these materials behave under different loading conditions including fatigue and impact loading. Low velocity impact damage can cause a quite complex damage scenario where different failure modes, such as matrix cracking, delamination, fibre breakage and fibre pull-out, can be present. The impact response of natural fibre composites has been the subject of several investigations [9-11] and the results, despite being promising, have highlighted peculiar damage mechanisms compared to traditional synthetic counterparts [12-14]. Therefore, it is of utmost importance to have a better understanding of the effects of various failure modes on the structural performance of natural fibre laminates in order to realize their full potential. As a result of significant moisture absorption, it is not usually advisable to use standard contact ultrasonic methods. The development of air-coupled ultrasonic techniques has made ultrasonic methods more feasible for defect detection in several materials, ranging from wood $[15,16]$, composite materials [17], metals [18] and food products [19]. The main disadvantage is that only a small fraction of the acoustic energy can be coupled into the specimen due to the large difference in impedance between air and solid materials, a problem that has been effectively faced by using increased emission energy and transducers with high sensitivity.

Another non-contact ultrasound testing uses optical excitation and detection of ultrasound with suitable lasers, the so-called Laser Ultrasonics (LUS) [20,21]. LUS is a non-contact method, without requiring any couplants, which can rapidly scan large areas and it is able to inspect at angles far off normal. The absorption of nanosecond-timescale laser pulses generates extremely short ultrasound transients, either via ablation or thermoelastic expansion and subsequent relaxation [22,23]. These transients cause well-defined echoes, which can be separated with high temporal resolution, allowing for single-sided testing with a broadband detection method. Today, this is usually realized through the measurement of surface vibrations with suitable optical interferometers, with detection bandwidths in excess of $100 \mathrm{MHz}$.

A disadvantage of this LUS implementation is that its performance is strongly dependent on the optical properties as well as on the surface characteristics of the sample under test, both for excitation and for detection. For strongly scattering surfaces, high powered detection lasers are needed as well as complex interferometer set-ups, which may be costly and difficult to miniaturize. In the present work, a novel method based on air-coupled detection of laser-generated ultrasound with a broadband optical microphone [24] is discussed and implemented for impact damage assessment in composites based on flax fibres and poly (lactic acid) (PLA) modified with 
polypropylene (PP) to improve its ductility. The air-coupled detection mechanism has the main advantage of being nearly independent of surface characteristics and optical properties of the sample. The results are compared with those obtained with an airborne ultrasound testing system and micro-CT.

\section{Optical microphone for air-coupled ultrasound detection - theoretical background}

The optical microphone is an acoustic detector to measure sound pressure waves in the range of 5 $\mathrm{Hz}$ to $1 \mathrm{MHz}$ in air and $20 \mathrm{MHz}$ in fluids without any moving mechanical parts. Thereby, changes in the refractive index of the optical medium, caused by the incoming pressure wave, are measured using an interferometer. This so-called Fabry-Pérot etalon consists of two semipermeable mirrors which are arranged at a fixed distance of $2 \mathrm{~mm}$. To achieve constructive interference conditions this distance matches a multiple of the half laser's wavelength. This condition for the wavelength is fulfilled at all times with the help of a slowly acting PID circuit, locking the laser to the cavity by tuning the laser current. While the incoming pressure wave changes the refractive index and thereby the optical path length of the miniaturized interferometer, the transmitted intensity of the laser decreases. This effect can be precisely detected by a photodiode; it corresponds directly to the acoustic pressure. The principle of operation is shown schematically in figure 1, while a photo of the sensor head is shown in figure 2.

Without any mechanically movable parts (such as membranes, deformable crystals, or similar), the optical microphone overcomes physical limitations of alternative solutions like piezoelectric transducers such as mechanical resonances and limited frequency bandwidth. The novel optoacoustic sensor enables a broadband, highly sensitive airborne pressure detection with a dynamic range expanding over $100 \mathrm{~dB}$ (5 decades). The detection principle is inherently linear and allows a high temporal resolution of less than $1 \mu$ s. Furthermore, the sensor head is very small having a size of a few millimeters only. This allows testing in confined spaces, nooks, or close to edge in an elbow-shaped element or a T-joint. Finally, the all-optical sensor head is immune to electromagnetic interferences (which might be present in the testing environment). On the other hand, the transmission of high ultrasonic frequencies through air is limited. While acoustic signals of frequencies in the human hearing range can easily propagate over hundreds of meters in air, a frequency of $1 \mathrm{MHz}$ is attenuated by as much as $160 \mathrm{~dB} / \mathrm{m}$ [25]. Hence, the optical microphone has to be brought close to the surface of the specimen (millimeters to centimeters), and the setup is not suitable for remote sensing. However, given the small size of the fiber-coupled sensor head, this condition could be easily achieved in all the performed tests. It was found that, in laser-excited CFRP measurements, the acoustic energy centers in the lower few-hundreds $\mathrm{kHz}$ range (further 
investigations are necessary to derive exact values). While the lateral resolution of the scans using the optical microphone can be clearly below $1 \mathrm{~mm}$ due to the small physical dimensions of the receiver, the depth resolution via time-of-flight is limited by the bandwidth of the receiver.

\section{Materials and methods}

\subsection{Materials}

Biotex Flax/PLA $400 \mathrm{~g} / \mathrm{m}^{2} 2 \times 2$ Twill supplied by Composites Evolution Ltd has been used to manufacture the samples. These fabrics are commingled textiles made from flax fibre and polylactic acid (PLA) and are suitable for producing fibre reinforced thermoplastic composite parts. PLA is a biodegradable thermoplastic polyester with its high strength but low toughness and heat resistance. These weaknesses can be tackled with several approaches, including plasticization, copolymerization, and melt blending with different tough polymers [26-28]. In this study, polypropylene (PP) (MA712 by Unipetrol, Czech Republic; MFI at $230{ }^{\circ} \mathrm{C}, 2.16 \mathrm{~kg}=12 \mathrm{~g} / 10 \mathrm{~min}$ ) was used to improve the toughness of such composite material via a film stacking process.

\subsection{Composite materials manufacturing}

Laminates have been manufactured by compression moulding (Collin GmbH (Edersberg, Germany) mod. P400E), using the film stacking method by alternating PP films with dry PLA/Flax layers with the following stacking sequence: $(0 / 90)_{6 s}$. During this process, the impregnation of the porous fabric by infiltration of a viscous polymer liquid is mainly carried out in the transverse direction rather than in-plane. This process is affected not only by the applied pressure but also by temperature boundary conditions used in heating and cooling in order to ensure (i) melting of the polymer without thermal degradation, (ii) impregnation of the reinforcing structure and (iii) consolidation of the laminate [29]. Therefore, the compression moulding has been carried out in accordance with the pre-optimized temperature and pressure profiles reported in figure 3, to allow for correct impregnation of the fabric layers, which is driven by the rheological behaviour at melt processing temperature. Plates with a thickness of $4.1 \pm 0.1 \mathrm{~mm}$ and a fibre volume fraction of $0.32 \pm 0.02$ have been cut to the required dimensions to perform the mechanical characterization. As a reference material, laminates without PP have been also manufactured with the same procedure.

\subsection{Mechanical characterization of composites}

Tensile tests have been carried out in accordance with ASTM D3039, with a gauge length of $50 \mathrm{~mm}$ and in displacement control with a cross-head speed of $2.5 \mathrm{~mm} / \mathrm{min}$. Three-point bending tests have been performed in accordance with ASTM D790 with a support span length of $80 \mathrm{~mm}$ and a cross- 
head speed of $2.5 \mathrm{~mm} / \mathrm{min}$. Both quasi-static mechanical tests have been carried out on a Zwick/Roell Z010 universal testing machine equipped with a $10 \mathrm{kN}$ load cell.

Test coupons measuring $100 \times 100 \mathrm{~mm}$ were at first impacted at room temperature up to perforation and then at target impact energies from 1 to $5 \mathrm{~J}$ to find the barely visible impact damage (BVID) threshold. An instrumented drop-weight impact testing machine (CEAST Fractovis) was used to this purpose equipped with a hemispherical tip (diameter of $19.8 \mathrm{~mm}$ ). A constant mass of $3.64 \mathrm{~kg}$ was used to deliver the required impact energy levels. Measurements were carried out on square samples simply supported on a steel cylindrical support with an internal hole $80 \mathrm{~mm}$ in diameter, according to the ASTM D5628. The force-time and force-displacement curves were recorded during each test by the DAS16K acquisition program. While BVID is subjective by nature, it is often defined as damage visible within a range of $1 \mathrm{~m}$, or damage causing a specific permanent indentation. The depth of the residual indentation caused by BVID varies in literature and in this study $0.3 \mathrm{~mm}$ of dent depth was chosen as the threshold of detectability (as commonly adopted by aeronautical standards). Post-impact, the dent depth of each coupon was measured using a laser profilometer (Taylor-Hobson Talyscan 150) with a scanning speed of $8500 \mu \mathrm{m} / \mathrm{s}$.

\subsection{Non-destructive testing setup}

The Laser Ultrasound setup consists of a fibre-coupled excitation laser, the optical microphone, a mechanical scanner and a control unit. The setup is shown in figure 4. The excitation laser generates a thermoelastic ultrasound wave within the probe, below the ablation threshold, in order not to damage the specimen. The generated ultrasound signal was measured in transmission mode, but might be also measured in a single sided approach - so called pitch-catch, or pulse-echo. A mechanical scanner unit is used to move the sensor and the excitation laser over the sample. The used stepping size is $0.2 \mathrm{~mm}$, the sampling rate is $25 \mathrm{MHz}$. No averaging or post-processing methods were exploited.

\subsection{Morphological and damage investigation}

The fracture surfaces of specimens failed in tension were investigated by scanning electron microscopy (FE-SEM Zeiss Auriga). All specimens were sputter coated with chromium prior to FESEM observations.

The volumetric damage visualization has been performed by X-ray microtomography (UltraTom CT scanner manufactured by RX Solutions) with a resolution of $20 \mu \mathrm{m} /$ voxel. The system consists 
of a Hamamatsu sealed type microfocus X-ray tube operating at 40-150 kV/0-500 $\mu \mathrm{A}$, within a maximum power of $75 \mathrm{~W}$.

\section{Results and discussion}

The potential of an air-coupled detection of laser-generated ultrasound using a broadband optical microphone in providing information about the probability of damage existence and its extension in natural fibre composites is discussed. For the sake of completeness, a quasi-static mechanical characterization of the material system under investigation will be described in the following before addressing the impact behaviour.

\subsection{Quasi-static mechanical properties}

The rationale for modifying the PLA with layers of PP was to explore the effect that a ductile polymer had upon the mechanical properties of flax fibre reinforced PLA composites. Table 1 summarizes the tensile and flexural properties, while figure 5 shows representative stress-strain curves obtained in tests at room temperature. The mechanical properties in tension compare quite favourably with those reported in the technical data sheet for the PLA/flax system. Despite a limited decrease in tensile modulus due to the addition of PP, as expected, no significant effect on the strength was noted. Flax fibres are known to show the presence of defects, kink bands, which act as stress concentration points in the matrix [30]. A stress concentration that could have been partially relieved by the increased matrix ductility, the net effect of this being the slight increase in tensile strength of the modified composites. The bending tests highlighted a slightly different behaviour with a decrease in flexural strength, likely ascribed to the complex state of stress and the strong dependence of flexural properties on the stacking sequence (i.e., location of PP layers), even if in both configurations the failure was located on the tensile side. The results suggest that in order to exploit to a larger extent a marked improve in toughness of the resulting composites, an optimization of the location and amount of PP layers would be needed. It is worth mentioning that both tensile and flexural curves exhibited a marked non-linear behaviour at low strains, which cannot be only due to the presence of the ductile PP in the brittle PLA, because also the unmodified flax/PLA system showed the same trend. It is reasonable to ascribe such behaviour to the presence of flax fibres, as reported by many authors [31-33], and it seems to be a characteristic of natural fibres, as it has been observed in wood [34,35], flax [36-38] and hemp [39-41]. A conclusive explanation has not yet been proposed, even if recent studies have shed light on the possible mechanisms, including viscoelastic strain, cellulose microfibrils reorientation, shear strain-induced crystallisation of the amorphous paracrystalline components and degree of ellipticity of the fibre's 
cross-section [41,42]. As a general comment, all composite configurations exhibited a macroscopically brittle behaviour, which is confirmed also at the micro-scale (figure 6). Scanning electron microscopy of the fracture surface of the Flax/PLA-PP system revealed that there was a sufficient but non-homogeneous level of adhesion between the fibre and matrix as evidenced by the presence of limited fibre pull-out (figure 6a) and debonding (figures $6 \mathrm{~b}$ and $\mathrm{c}$ ) with fracture surface exhibiting a "blocky" appearance (figures $6 \mathrm{~b}$ and c) with fibres fractured on the same plane. It is also possible to note the presence of ligaments connecting the fibres to the matrix (figure $6 \mathrm{~d}$ ), this would support the good mechanical behaviour exhibited by the biocomposites. From the micrographs, it is also evident that no significant phase separation occurred, despite the fact that PLA and PP are immiscible because of the high polarity difference between the component polymers [43].

\subsection{Low-velocity impact behaviour}

Starting from the positive results of the quasi-static mechanical characterization, impact tests were performed under various impact energies ranging from $1 \mathrm{~J}$ to $5 \mathrm{~J}$ in order to examine damage evolution in Flax/PLA-PP laminates. These impact energies were selected according to the knowledge of the perforation threshold, which was found to be equal to $13.99 \pm 1.63 \mathrm{~J}$ with a peak force of $2160.94 \pm 90.98 \mathrm{~N}$, in line with recent investigations $[13,44]$. The relatively low perforation threshold suggested the selection of impact energies in the range $1 \mathrm{~J}-5 \mathrm{~J}$ in order to induce significant damage in the laminates while being sufficiently far from the penetration. Parameters like impact force, sample deflection, impact velocity, impact energy $\left(E_{i}\right)$ and absorbed energy $\left(E_{a}\right)$ were obtained by the data acquisition system. In particular, the absorbed energy in the impact event was calculated as the area enclosed in the load-deflection curve, which also includes some useful information for assessing damage process of composite structures [45]. In impacts at perforation, not only the matrix but also the fibres play a significant role in the energy absorption process during an impact event. In the present case, flax fibres are on average weaker than glass or carbon fibres, and therefore the relative contribution of the matrix to the global composite impact response is much more important. Visual inspection of perforated samples, shown in figure 7, supports these results. It can be seen that samples failed with a sharp failure pattern ascribed to a predominantly brittle failure mechanism, as already observed in tensile and bending tests. During impact, parts of the samples broke away leaving a clean hole on the front face and a cross-shaped, pyramidal deformation on the back side.

Figure 8 shows typical force-displacement curves as a function of impact energy. The curves appear to be closed, with displacement returning toward the axis origin during unloading, thus meaning 
that some elastic energy is recovered by the laminate. These flax laminates exhibited a significant energy absorption capability, increasing with increasing impact energy, due to a slightly enhanced compliant behaviour but mainly due to the development of a significant internal damage, as confirmed by the presence of an extended plateau at the peak load, with the exception of $1 \mathrm{~J}$-impact. In addition, the peak load was found to be very dependent on impact energy, with an increase as the energy level increased up to perforation. Key impact parameters like peak force, impact energy $\left(E_{i}\right)$, absorbed energy $\left(\mathrm{E}_{\mathrm{a}}\right)$ and damage degree $\left(\mathrm{E}_{\mathrm{a}} / \mathrm{E}_{\mathrm{i}}\right)$ obtained from the transient response of each laminate are summarized in table 2. The damage degree [46] increased significantly from $1 \mathrm{~J}$ to $5 \mathrm{~J}$, thus confirming the quasi-brittle behaviour of the laminates, which tend to absorb energy through the development of internal damage. In terms of impact damage, it was found that Flax/PLA-PP laminates reached indentation levels implying BVID already at $5 \mathrm{~J}$, as can be clearly observed in table 2, while figure 9 shows the impacted surface of the samples as obtained from laser profilometry from which the dent depth was calculated.

\subsection{Analysis of damage}

Figure 10 shows the different damage patterns of laminates tested at increasing impact energy. By visual inspection, only a contact-induced indentation without edge delaminations around the impact point was detected at each impact energy on the front face. Damage was localized in the back face and exhibited a cross-shaped feature typical of woven laminates, following the warp and weft direction of the fabric and mainly caused by the failure of the flax yarns and the matrix [44]. This behaviour can be ascribed to the combined effect of the bending and membrane tensile forces. As impact energy increases, the extension of damage was found to increase in the back face. Hardly detectable damage was found in laminates impacted at $1 \mathrm{~J}$. As regards the internal damage, two recent publications have highlighted different damage patterns in flax reinforced laminates impacted with a combination of masses and impactor geometry similar to the one used in the present study $[13,44]$. With the exception of inevitable differences in thickness and fibre volume fraction, in a Flax/PLA composite the main failure mechanism found was fibre failure without transverse cracks and delaminations [44]. Bensadoun et al. [13], when comparing the impact performance of epoxy and maleic anhydride polypropylene (MAPP) reinforced with flax fibres, emphasized the presence of extended through-the-thickness cracks with fibre failure and limited delaminations. In order to shed light into the damage modes of the Flax/PLA-PP laminates, all the samples were inspected by X-ray microtomography and representative images are reported in figures 11 and 12. Even with micro-CT, the specimen impacted at $1 \mathrm{~J}$ showed only a small dent on the impacted surface without evidence of additional damage mechanisms. Specimens impacted with 
energy levels in the range $2 \mathrm{~J}-5 \mathrm{~J}$ exhibited the typical "pine tree" damage pattern [47], which includes matrix cracks due to shear and bending along with extensive delaminations. The damage had a conical appearance in the thickness direction with the in-plane damage area that increased from the impact surface to the rear one. This is a damage pattern usually found in thick laminates [48]. In particular, the extent of transverse matrix cracks, ascribed to the relatively low strength of flax fibres, appears to be significant, thus potentially leading to a decrease in laminates' stiffness.

Ultrasonic C-scan represents the standard approach for assessing the damage in composite laminates subjected to impact loading, but the need to use a coupling fluid prevents or at least limits its use in the field of natural fibre composites that are particularly prone to moisture absorption. In this regard, a novel system based on air-coupled detection of laser-generated ultrasound with an optical microphone has been used to inspect the Flax/PLA-PP laminates. The results are summarized in figure 13 along with a comparison with another non-contact method based on piezoelectric excitation in figure 14. It can be seen that laser-UT enables a better detection of low velocity impact damages compared to airborne ultrasound with a better-defined damaged area. It is also worth mentioning that laser-UT pointed out the presence of a small damaged area even in the specimens impacted at $1 \mathrm{~J}$, which was not easy to be detected by micro-CT, visual inspection or aircoupled piezoelectric excitation. This innovative set-up allows for the implementation of compact, fibre-coupled NDT probes suited for the detection and generation of $\mu$ s-timescale ultrasound transients with acquisition speed of $1 \mathrm{kHz}$, well suited for fast inline NDT inspection of composites and in particular of natural fibre composites.

\section{Conclusions}

The objective of this experimental work was to assess the impact damage in Flax/PLA-PP composites and propose a non-contact, non-destructive testing setup based on laser excitation of ultrasound and detection with a broadband, air-coupled optical microphone for its detection. In particular, a commercial Flax/PLA laminate modified with the addition of PP has been used as a reference material once subjected to low velocity impacts in the range $1 \mathrm{~J}-5 \mathrm{~J}$. Damage mechanisms were detailed by visual inspection and micro-CT and complemented by the results provided by the laser-UT, which proved to be more sensitive to damages caused by low energy impacts. These preliminary results demonstrated that this set-up allows high-resolution imaging of defects in through-transmission mode. Future work will address single-sided setups, as well as an array configuration, where 8 optical microphones are arranged with a pitch of $2 \mathrm{~mm}$, to increase scanning speed and allow for beamforming algorithms. 


\section{Data availability}

The raw/processed data required to reproduce these findings cannot be shared at this time as the data also forms part of an ongoing study. 


\section{References}

[1] Richardson MOW, Wisheart MJ. Review of low-velocity impact properties of composite materials. Compos Part A Appl Sci Manuf 1996;27:1123-31. doi:10.1016/1359835X(96)00074-7.

[2] Sfarra S, Cicone A, Yousefi B, Ibarra-Castanedo C, Perilli S, Maldague X. Improving the detection of thermal bridges in buildings via on-site infrared thermography: The potentialities of innovative mathematical tools. Energy Build 2019;182:159-71. doi:10.1016/J.ENBUILD.2018.10.017.

[3] Zhang H, Avdelidis NP, Osman A, Ibarra-Castanedo C, Sfarra S, Fernandes H, et al. Enhanced Infrared Image Processing for Impacted Carbon/Glass Fiber-Reinforced Composite Evaluation. Sensors (Basel) 2017;18. doi:10.3390/s18010045.

[4] Cawley P. Inspection of Composites-Current Status and Challenges. Eur. Conf. Non Destr. Test., Berlin, Germany: 2006, p. 1-10.

[5] Hsu DK. Nondestructive Inspection of composite structures: methods and practice. 17th World Conf. Nondestruct. Test., Shanghai, China: 2008, p. 1-13.

[6] Pickering KL, Aruan Efendy MG, Le TM. A review of recent developments in natural fibre composites and their mechanical performance. Compos Part A Appl Sci Manuf 2016;83:98112. doi:10.1016/j.compositesa.2015.08.038.

[7] Fortea-Verdejo M, Bumbaris E, Burgstaller C, Bismarck A, Lee KY. Plant fibre-reinforced polymers: where do we stand in terms of tensile properties? Int Mater Rev 2017;62:441-64. doi:10.1080/09506608.2016.1271089.

[8] Lucintel. Growth Opportunities in the Global Natural Fiber Composites Market. 2015.

[9] Liang S, Guillaumat L, Gning P-B. Impact behaviour of flax/epoxy composite plates. Int J Impact Eng 2015;80:56-64. doi:10.1016/J.IJIMPENG.2015.01.006.

[10] Huber T, Bickerton S, Müssig J, Pang S, Staiger MP. Flexural and impact properties of allcellulose composite laminates. Compos Sci Technol 2013;88:92-8. doi:10.1016/j.compscitech.2013.08.040.

[11] Dhakal HN, Zhang ZY, Bennett N, Reis PNB. Low-velocity impact response of non-woven hemp fibre reinforced unsaturated polyester composites: Influence of impactor geometry and 
impact velocity. Compos Struct 2012;94:2756-63.

doi:10.1016/J.COMPSTRUCT.2012.04.004.

[12] Dhakal H, Ghasemnejad H, Zhang Z, Ismail S, Arumugam V. The post-impact response of flax/UP composite laminates under low velocity impact loading. Int J Damage Mech 2018:105678951775123. doi:10.1177/1056789517751239.

[13] Bensadoun F, Depuydt D, Baets J, Verpoest I, van Vuure AW. Low velocity impact properties of flax composites. Compos Struct 2017;176:933-44.

doi:10.1016/J.COMPSTRUCT.2017.05.005.

[14] Sarasini F, Tirillò J, D’Altilia S, Valente T, Santulli C, Touchard F, et al. Damage tolerance of carbon/flax hybrid composites subjected to low velocity impact. Compos Part B Eng 2016;91:144-53. doi:10.1016/j.compositesb.2016.01.050.

[15] Fang Y, Lin L, Feng H, Lu Z, Emms GW. Review of the use of air-coupled ultrasonic technologies for nondestructive testing of wood and wood products. Comput Electron Agric 2017;137:79-87. doi:10.1016/J.COMPAG.2017.03.015.

[16] Chimenti DE. Review of air-coupled ultrasonic materials characterization. Ultrasonics 2014;54:1804-16. doi:10.1016/J.ULTRAS.2014.02.006.

[17] Imielińska K, Castaings M, Wojtyra R, Haras J, Clezio E Le, Hosten B. Air-coupled ultrasonic C-scan technique in impact response testing of carbon fibre and hybrid: glass, carbon and Kevlar/epoxy composites. J Mater Process Technol 2004;157-158:513-22. doi:10.1016/J.JMATPROTEC.2004.07.143.

[18] Waag G, Hoff L, Norli P. Air-coupled ultrasonic through-transmission thickness measurements of steel plates. Ultrasonics 2015;56:332-9.

[19] Pallav P, Hutchins DA, Gan T. Air-coupled ultrasonic evaluation of food materials. Ultrasonics 2009;49:244-53.

[20] Green R. J. Non-contact ultrasonic techniques. Ultrasonics 2004;42:9-16.

[21] Park B, An Y-K, Sohn H. Visualization of hidden delamination and debonding in composites through noncontact laser ultrasonic scanning. Compos Sci Technol 2014;100:10-8.

[22] Davies SJ, Edwards C, Taylor GS, Palmer SB. Laser-generated ultrasound: its properties, mechanisms and multifarious applications. J Phys D Appl Phys 1993;26:329-48. 
[23] Drake TE, Yawn KR, Chuang SY, Osterkamp MA. Affordable NDE of Aerospace Composites with Laser Ultrasonics. Rev. Prog. Quant. Nondestruct. Eval., 1998, p. 587-93.

[24] Fischer B. Optical microphone hears ultrasound. Nat Photonics 2016;10:356-8.

[25] Bass HE, Sutherland LC, Zuckerwar AJ. Atmospheric absorption of sound: Update. J Acoust Soc Am 1990;88:2019-21. doi:10.1121/1.400176.

[26] Krishnan S, Pandey P, Mohanty S, Nayak SK. Toughening of Polylactic Acid: An Overview of Research Progress. Polym Plast Technol Eng 2016;55:1623-52. doi:10.1080/03602559.2015.1098698.

[27] Kfoury G, Raquez J-M, Hassouna F, Odent J, Toniazzo V, Ruch D, et al. Recent advances in high performance poly(lactide): from "green" plasticization to super-tough materials via (reactive) compounding. Front Chem 2013;1:32. doi:10.3389/fchem.2013.00032.

[28] Nagarajan V, Mohanty AK, Misra M. Perspective on Polylactic Acid (PLA) based Sustainable Materials for Durable Applications: Focus on Toughness and Heat Resistance. ACS Sustain Chem Eng 2016;4:2899-916. doi:10.1021/acssuschemeng.6b00321.

[29] Mayer C, Wang X, Neitzel M. Macro- and micro-impregnation phenomena in continuous manufacturing of fabric reinforced thermoplastic composites. Compos Part A Appl Sci Manuf 1998;29:783-93. doi:10.1016/S1359-835X(98)00056-6.

[30] Hughes M, Carpenter J, Hill C. Deformation and fracture behaviour of flax fibre reinforced thermosetting polymer matrix composites. J Mater Sci 2007;42:2499-511. doi:10.1007/s10853-006-1027-2.

[31] Poilane C, Cherif ZE, Richard F, Vivet A, Ben Doudou B, Chen J. Polymer reinforced by flax fibres as a viscoelastoplastic material. Compos Struct 2014;112:100-12. doi:10.1016/J.COMPSTRUCT.2014.01.043.

[32] Berges M, Leger R, Placet V, Person V, Corn S, Gabrion X, et al. Influence of moisture uptake on the static, cyclic and dynamic behaviour of unidirectional flax fibre-reinforced epoxy laminates. Compos Part A Appl Sci Manuf 2016;88:165-77. doi:10.1016/J.COMPOSITESA.2016.05.029.

[33] Hughes M, Hill CAS, Hague JRB. The fracture toughness of bast fibre reinforced polyester composites Part 1 Evaluation and analysis. J Mater Sci 2002;37:4669-76. doi:10.1023/A:1020621020862. 
[34] Navi P, Rastogi P, Gresse V, Tolou A. Micromechanics of wood subjected to axial tension. Wood Sci Technol 1995;29:411-29. doi:10.1007/BF00194199.

[35] Keckes J, Burgert I, Frühmann K, Müller M, Kölln K, Hamilton M, et al. Cell-wall recovery after irreversible deformation of wood. Nat Mater 2003;2:810-3. doi:10.1038/nmat1019.

[36] Mahboob Z, El Sawi I, Zdero R, Fawaz Z, Bougherara H. Tensile and compressive damaged response in Flax fibre reinforced epoxy composites. Compos Part A Appl Sci Manuf 2017;92:118-33. doi:10.1016/J.COMPOSITESA.2016.11.007.

[37] Baley C. Analysis of the flax fibres tensile behaviour and analysis of the tensile stiffness increase. Compos Part A Appl Sci Manuf 2002;33:939-48. doi:10.1016/S1359$835 \mathrm{X}(02) 00040-4$.

[38] Aslan M, Chinga-Carrasco G, Sørensen BF, Madsen B. Strength variability of single flax fibres. J Mater Sci 2011;46:6344-54. doi:10.1007/s10853-011-5581-x.

[39] Placet V, Cisse O, Boubakar ML. Influence of environmental relative humidity on the tensile and rotational behaviour of hemp fibres. J Mater Sci 2012;47:3435-46. doi:10.1007/s10853011-6191-3.

[40] Placet V. Characterization of the thermo-mechanical behaviour of Hemp fibres intended for the manufacturing of high performance composites. Compos Part A Appl Sci Manuf 2009;40:1111-8. doi:10.1016/j.compositesa.2009.04.031.

[41] Placet V, Cissé O, Lamine Boubakar M. Nonlinear tensile behaviour of elementary hemp fibres. Part I: Investigation of the possible origins using repeated progressive loading with in situ microscopic observations. Compos Part A Appl Sci Manuf 2014;56:319-27. doi:10.1016/J.COMPOSITESA.2012.11.019.

[42] Del Masto A, Trivaudey F, Guicheret-Retel V, Placet V, Boubakar L. Nonlinear tensile behaviour of elementary hemp fibres: a numerical investigation of the relationships between 3D geometry and tensile behaviour. J Mater Sci 2017;52:6591-610. doi:10.1007/s10853017-0896-x.

[43] Choudhary P, Mohanty S, Nayak SK, Unnikrishnan L. Poly( L -lactide)/polypropylene blends: Evaluation of mechanical, thermal, and morphological characteristics. J Appl Polym Sci 2011;121:3223-37. doi:10.1002/app.33866.

[44] Rubio-López A, Artero-Guerrero J, Pernas-Sánchez J, Santiuste C. Compression after impact 
of flax/PLA biodegradable composites. Polym Test 2017;59:127-35.

doi:10.1016/J.POLYMERTESTING.2017.01.025.

[45] Belingardi G, Vadori R. Low velocity impact tests of laminate glass-fiber-epoxy matrix composite material plates. Int J Impact Eng 2002;27:213-29. doi:10.1016/S0734$743 \times(01) 00040-9$.

[46] Belingardi G, Cavatorta MP, Salvatore Paolino D. Repeated impact response of hand lay-up and vacuum infusion thick glass reinforced laminates. Int J Impact Eng 2008;35:609-19. doi:10.1016/j.ijimpeng.2007.02.005.

[47] Shyr T-W, Pan Y-H. Impact resistance and damage characteristics of composite laminates. Compos Struct 2003;62:193-203. doi:10.1016/S0263-8223(03)00114-4.

[48] Cantwell WJ, Morton J. Detection of impact damage in CFRP laminates. Compos Struct 1985;3:241-57. doi:10.1016/0263-8223(85)90056-X. 


\section{Tables}

Table 1. Summary of tensile and flexural properties for both configurations

\begin{tabular}{|l|c|c|c|c|c|c|}
\hline Specimen ID & $\begin{array}{c}\text { Tensile } \\
\text { modulus } \\
(\mathbf{G P a})\end{array}$ & $\begin{array}{c}\text { Tensile } \\
\text { strength } \\
\mathbf{( M P a )}\end{array}$ & $\boldsymbol{\varepsilon}_{\mathbf{f}, \mathbf{T}} \mathbf{( \% )}$ & $\begin{array}{c}\text { Flexural } \\
\text { modulus } \\
(\mathbf{G P a})\end{array}$ & $\begin{array}{c}\text { Flexural } \\
\text { strength } \\
\mathbf{( M P a )}\end{array}$ & $\boldsymbol{\varepsilon}_{\mathbf{f}, \mathbf{F}} \mathbf{( \% )}$ \\
\hline Flax/PLA & $14.11 \pm 1.41$ & $79.96 \pm 3.97$ & $1.09 \pm 0.13$ & $12.59 \pm 0.37$ & $130.48 \pm 2.58$ & $1.67 \pm 0.14$ \\
\hline Flax/PLA-PP & $12.48 \pm 1.17$ & $86.42 \pm 1.24$ & $1.36 \pm 0.07$ & $12.43 \pm 0.48$ & $124.96 \pm 5.17$ & $1.69 \pm 0.05$ \\
\hline
\end{tabular}

Table 2. Parameters obtained from impact tests on Flax/PLA-PP laminates

\begin{tabular}{|l|c|c|c|c|c|}
\hline $\begin{array}{l}\text { Energy } \\
\text { level }(\mathbf{J})\end{array}$ & Peak force (N) & $\mathbf{E}_{\mathbf{i}}(\mathbf{J})$ & $\mathbf{E}_{\mathbf{a}}(\mathbf{J})$ & $\begin{array}{c}\text { Damage } \\
\text { Degree }\end{array}$ & $\begin{array}{c}\text { Indentation } \\
(\boldsymbol{\mu m})\end{array}$ \\
\hline 1 & $1371.61 \pm 1.84$ & $0.95 \pm 0.01$ & $0.05 \pm 0.01$ & $0.05 \pm 0.01$ & $35.08 \pm 3.65$ \\
\hline 2 & $1510.74 \pm 26.54$ & $1.98 \pm 0.01$ & $0.59 \pm 0.08$ & $0.30 \pm 0.04$ & $240.23 \pm 9.85$ \\
\hline 3 & $1668.80 \pm 54.50$ & $3.00 \pm 0.01$ & $1.13 \pm 0.09$ & $0.38 \pm 0.03$ & $281.36 \pm 10.21$ \\
\hline 5 & $1877.86 \pm 17.62$ & $4.97 \pm 0.02$ & $2.32 \pm 0.05$ & $0.46 \pm 0.03$ & $415.02 \pm 12.43$ \\
\hline
\end{tabular}




\section{Figure captions}

Figure 1. Schematic working principle of the Fabry-Pérot based sensor

Figure 2. Image and actual size of the sensor head

Figure 3. Compression moulding cycle used to manufacture the composite materials

Figure 4. Laser Ultrasound setup in through-transmission mode

Figure 5. Typical stress vs. strain curves for natural fibre composites in tensile and bending tests

Figure 6. SEM micrographs of failed tensile Flax/PLA-PP specimens at different magnifications

Figure 7. Fracture behaviour of Flax/PLA-PP composite after a perforation impact event: (a) front face and (b) rear face

Figure 8. Representative force vs. displacement curves as a function of impact energy for Flax/PLA-PP laminates

Figure 9. Impacted surface of laminates as obtained by non-contact profilometry (a) $1 \mathrm{~J}$, (b) $2 \mathrm{~J}$, (c) $3 \mathrm{~J}$, (d) $5 \mathrm{~J}$ and (e) a representative profile for a $5 \mathrm{~J}$-impact

Figure 10. Close-up views of damage progression on front and rear faces of Flax/PLA-PP laminates

Figure 11. Typical micro-CT scans in the laminate plane for the Flax/PLA-PP laminates impacted at different energy levels

Figure 12. Typical micro-CT scans in the laminate thickness for the Flax/PLA-PP laminates impacted at different energy levels

Figure 13. Laser-UT C-Scans for the Flax/PLA-PP laminates impacted at different energy levels

Figure 14. Air-coupled UT C-Scans using piezoelectric excitation for the Flax/PLA-PP laminates impacted at different energy levels 


\section{Figures}

Figure 1

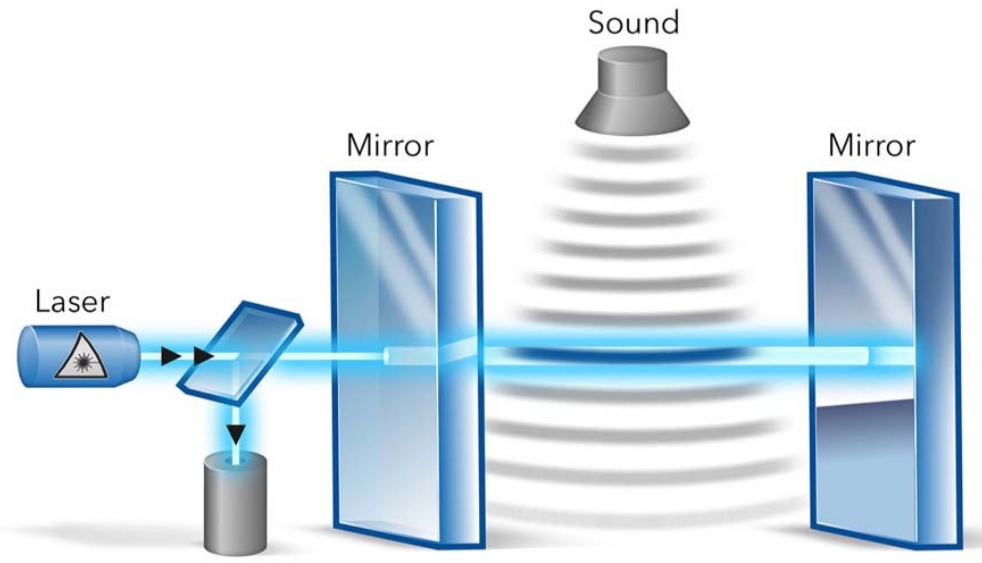

Figure 2

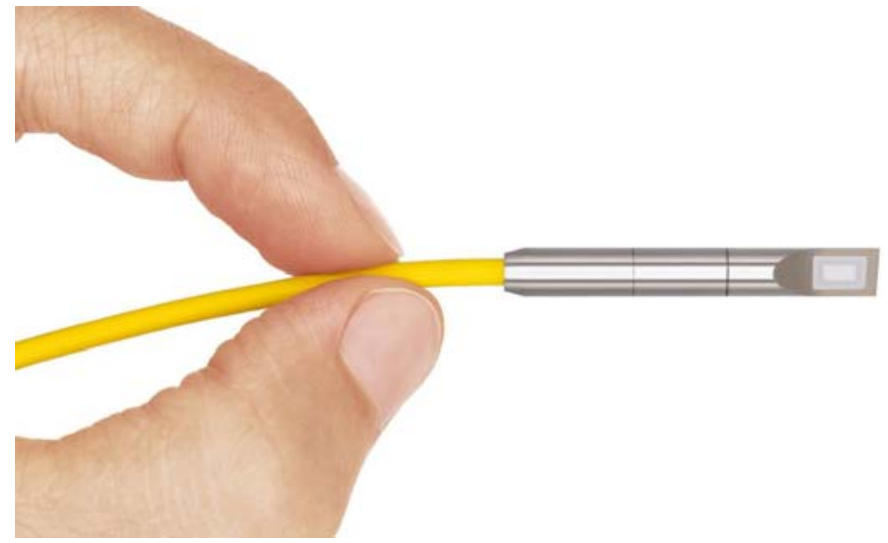


Figure 3

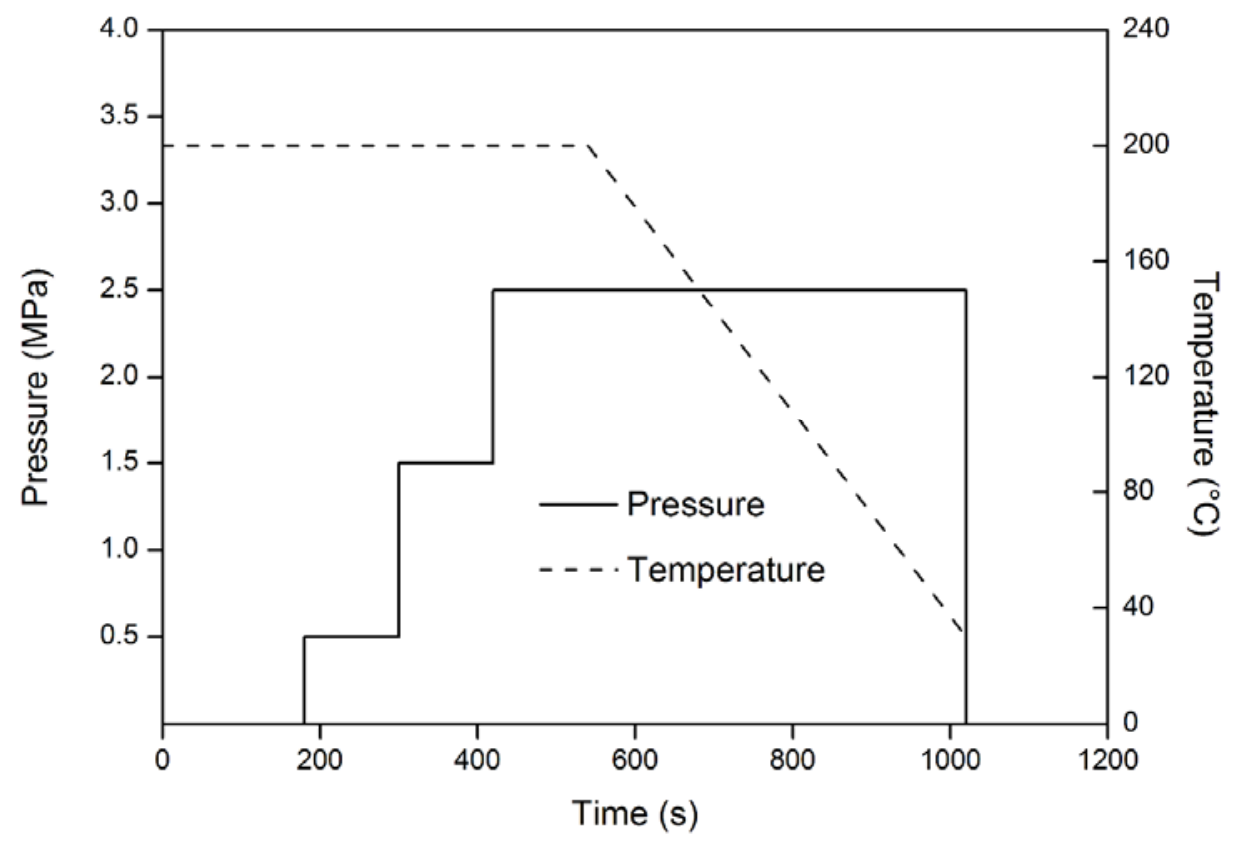

Figure 4

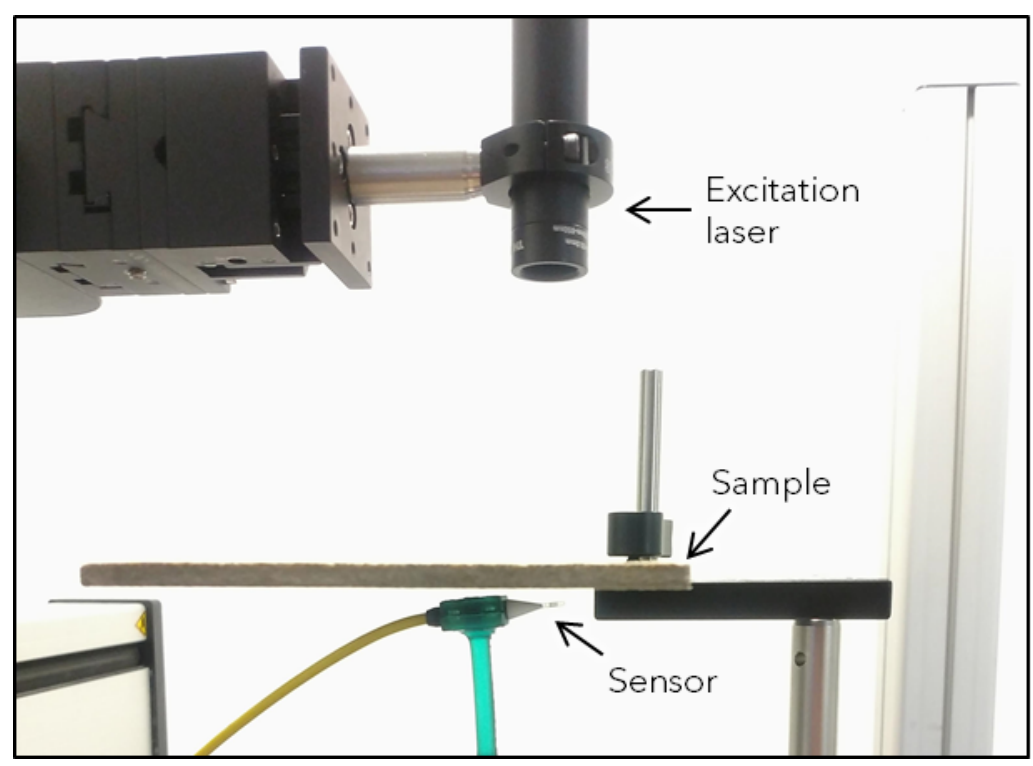


Figure 5
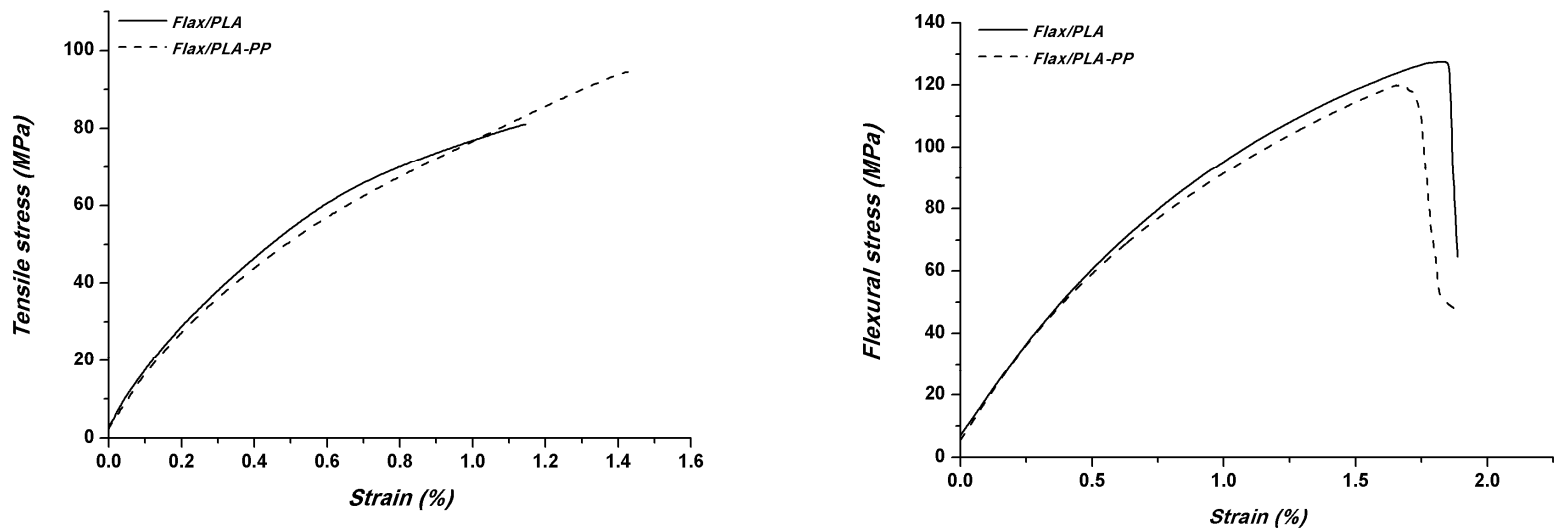

Figure 6

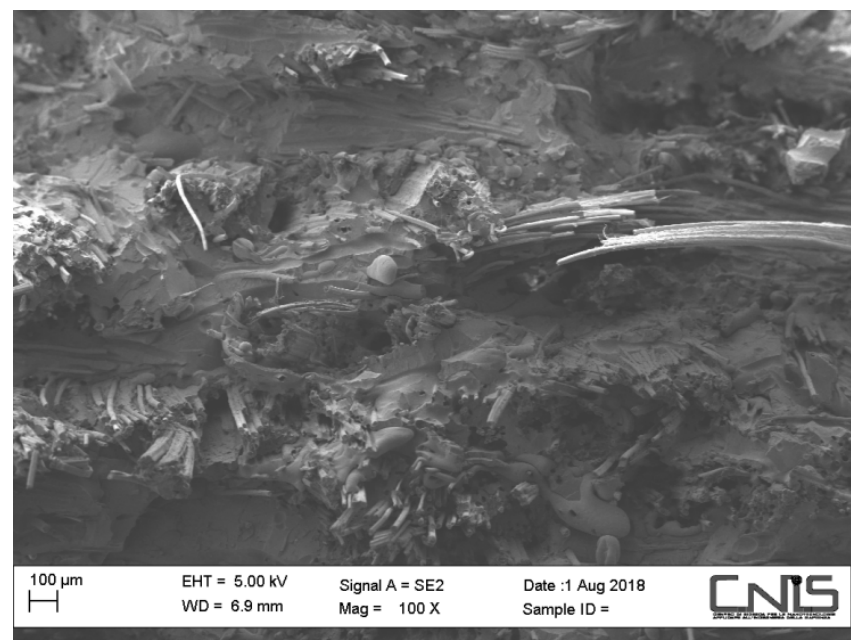

(a)

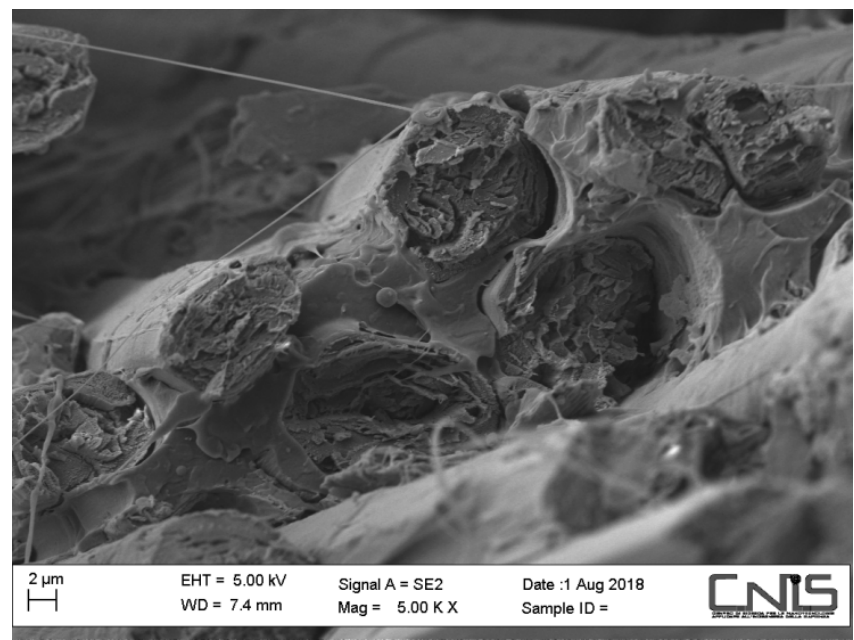

(c)

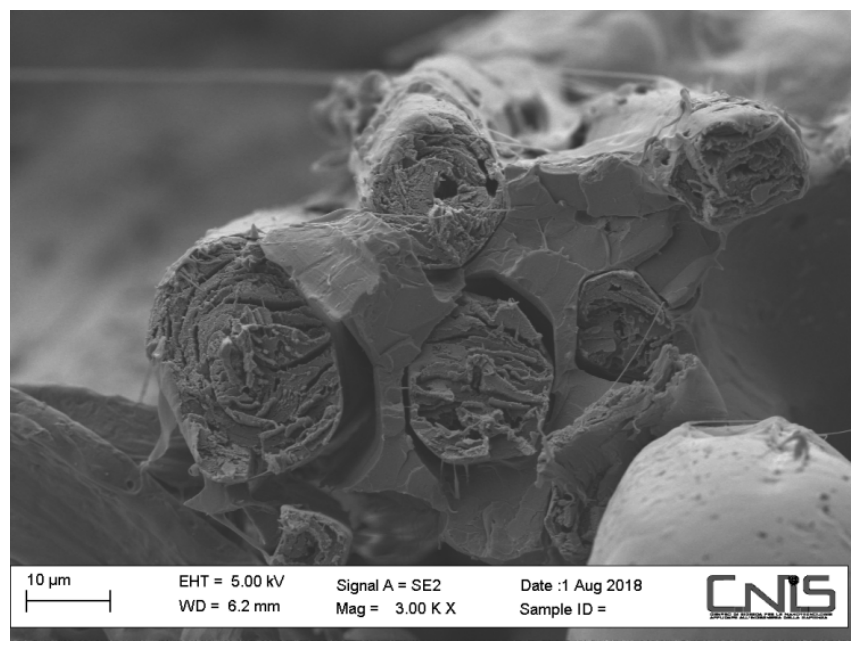

(b)

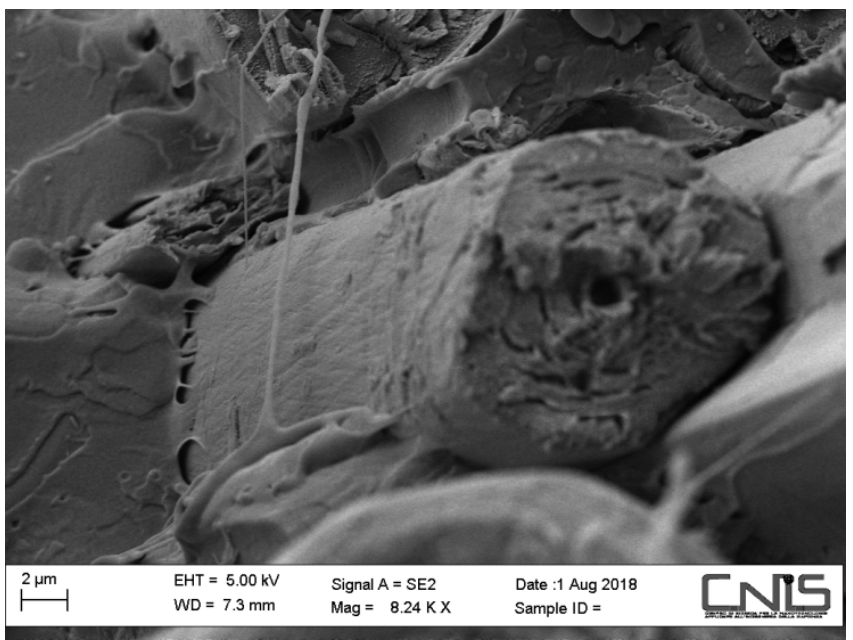

(d) 
Figure 7

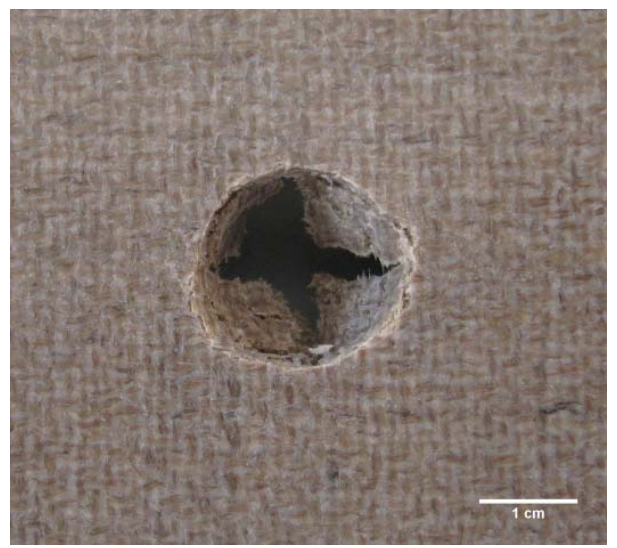

(a)

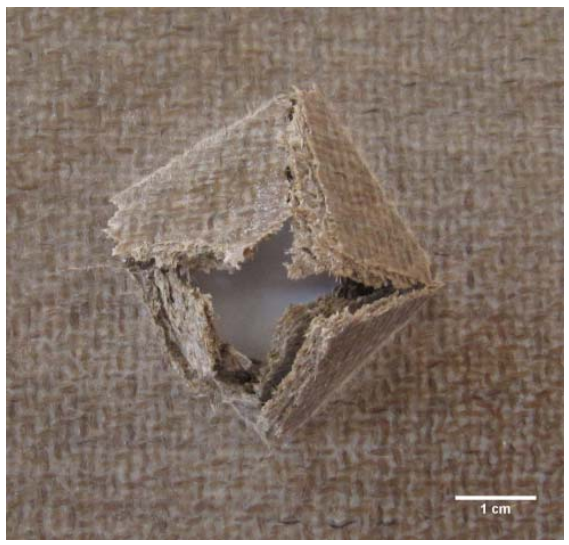

(b)

Figure 8

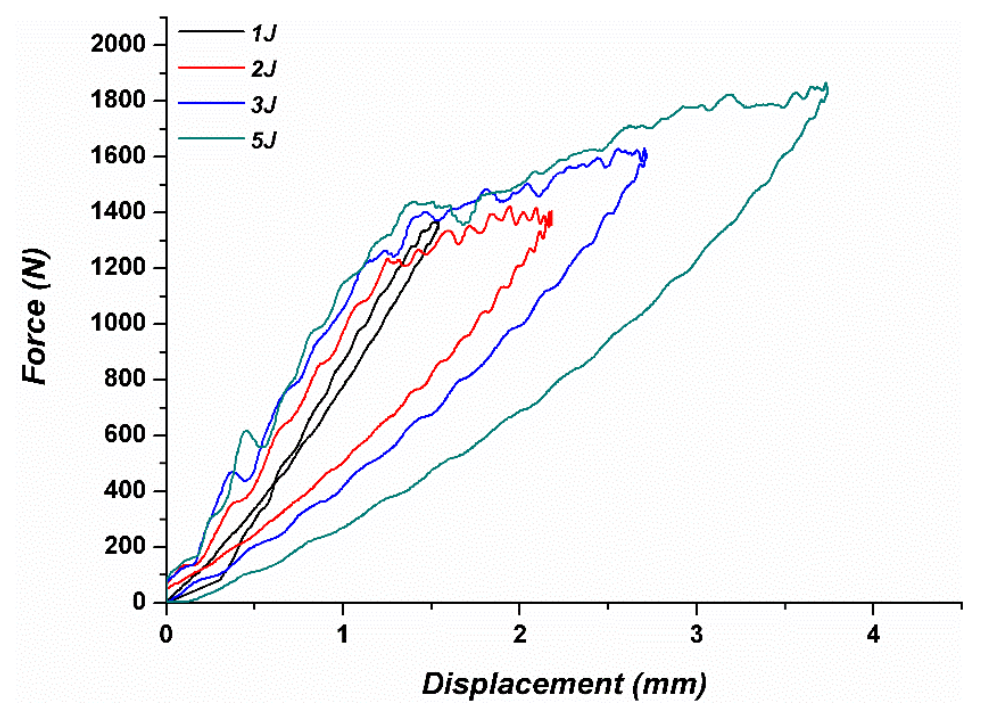

Figure 9

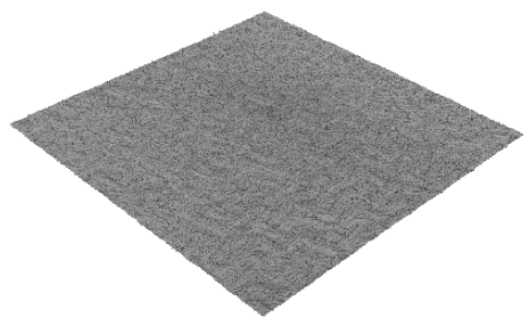

(a)
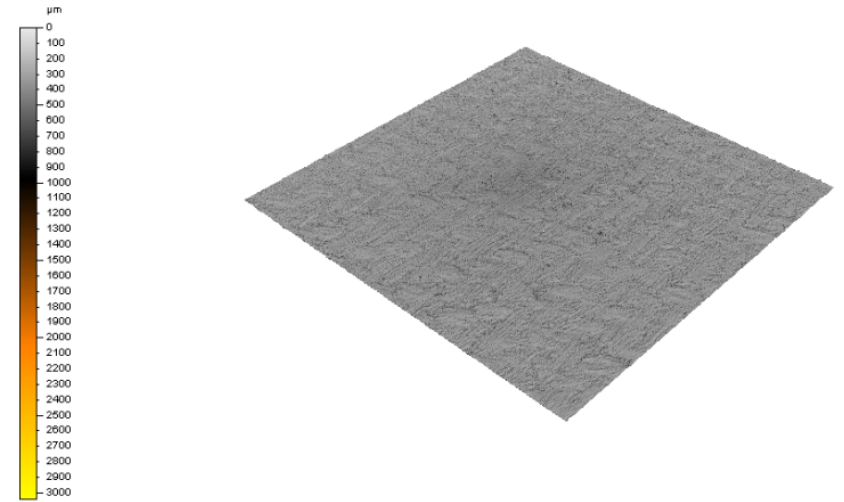

(b) 


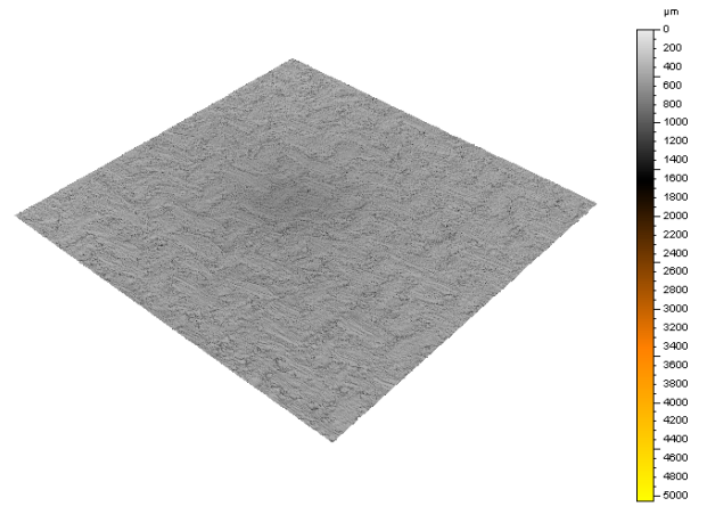

(c)

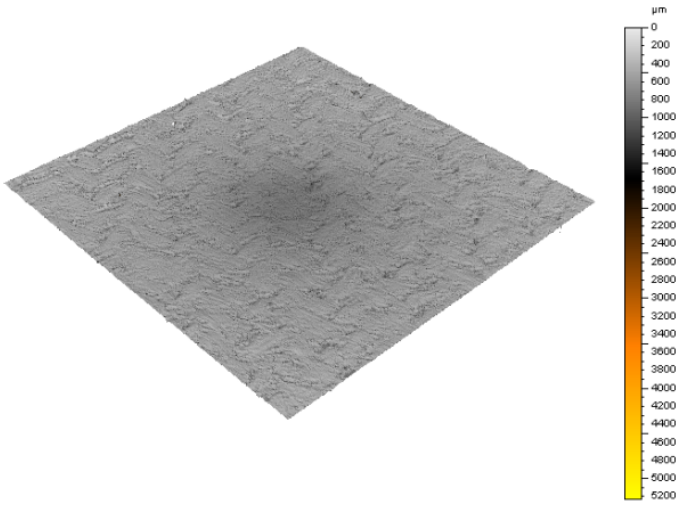

(d)

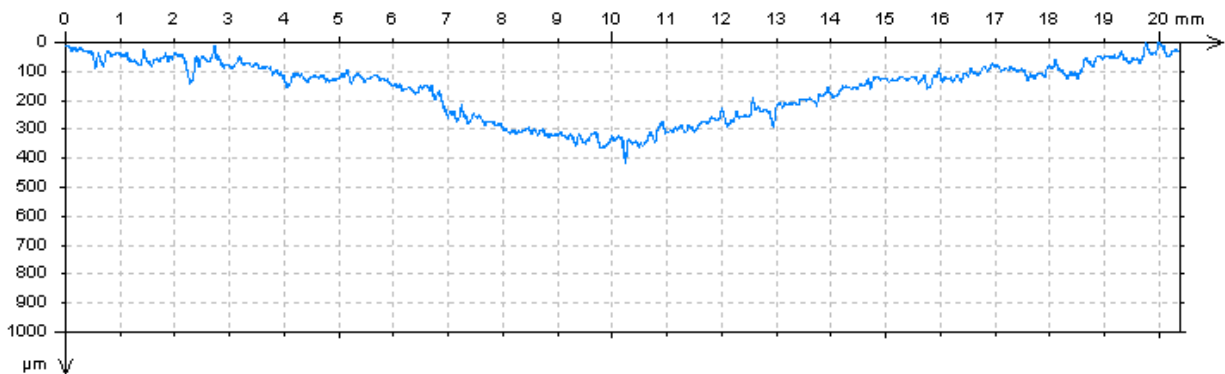

(e)

Figure 10
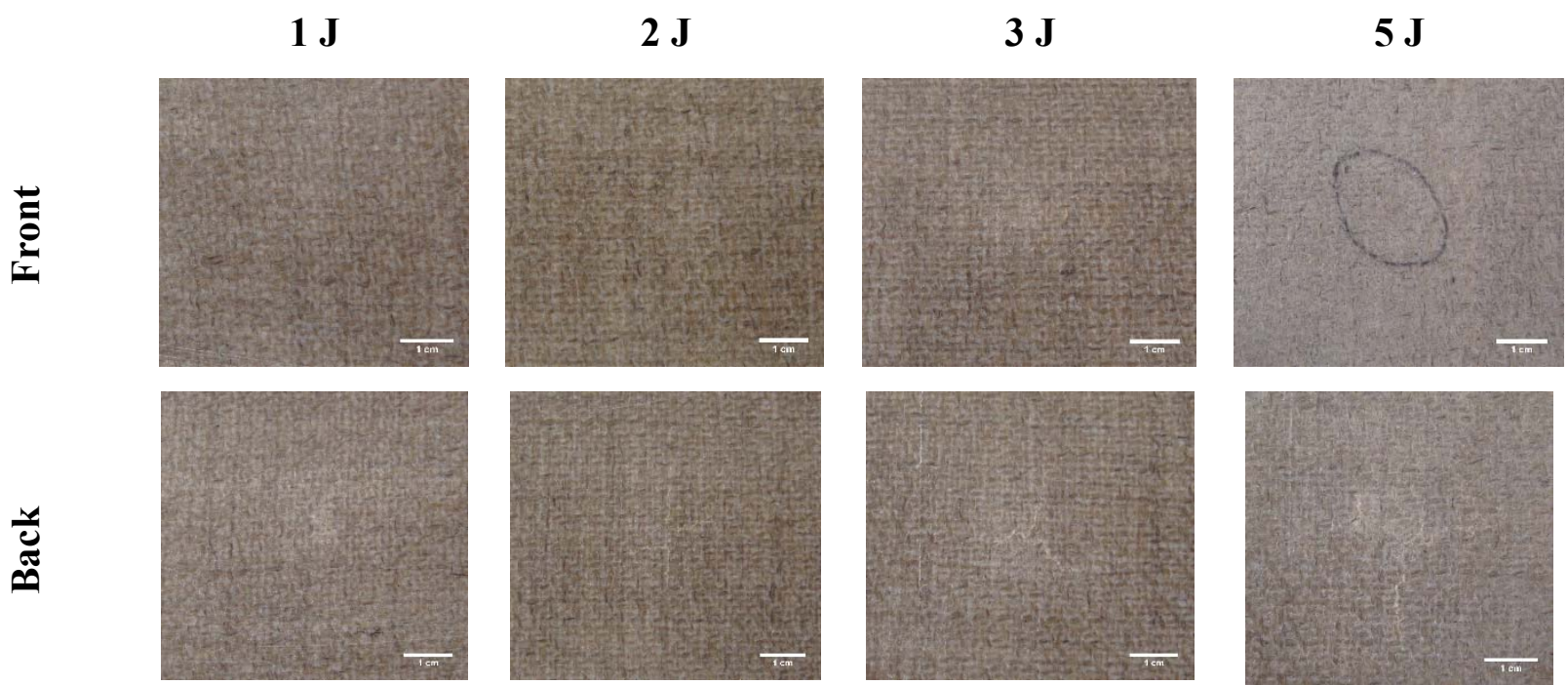
Figure 11

$1 \mathbf{J}$

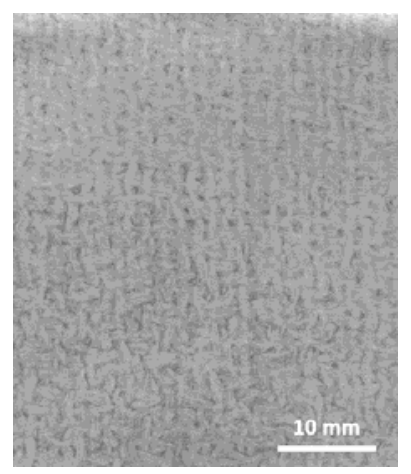

2 J

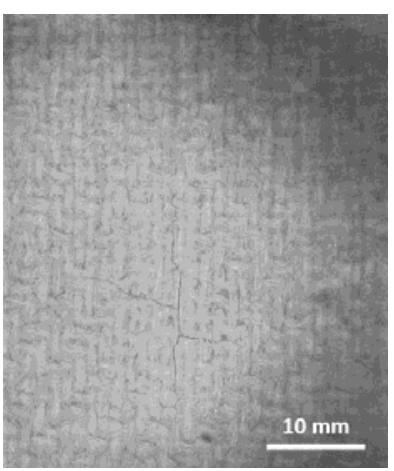

3 J

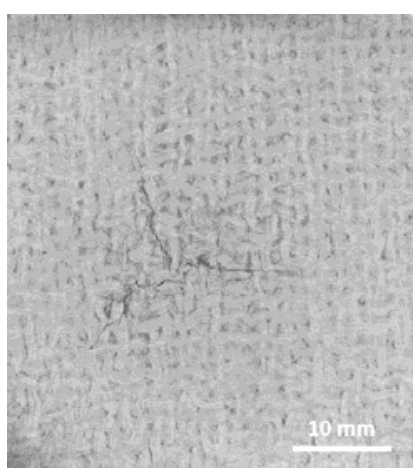

5 J

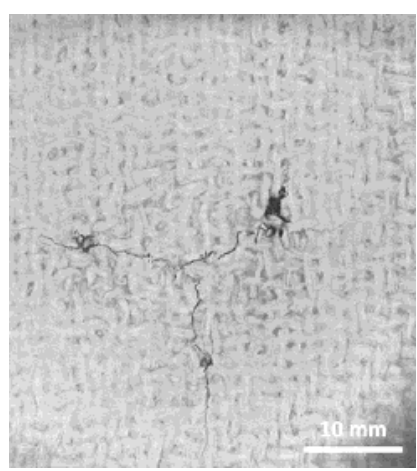

Figure 12

\section{$1 \mathrm{~J}$}

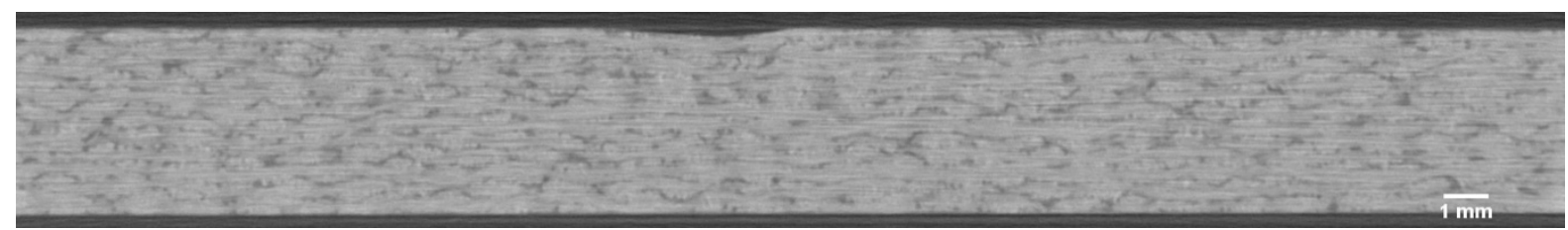

2 J

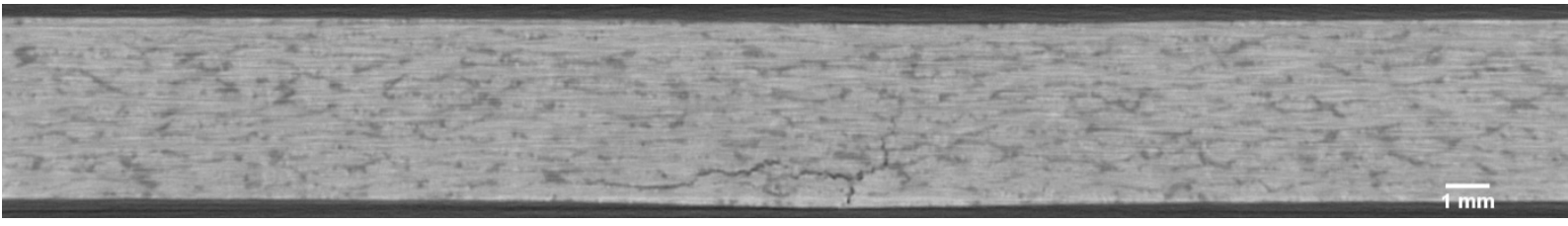

3 J

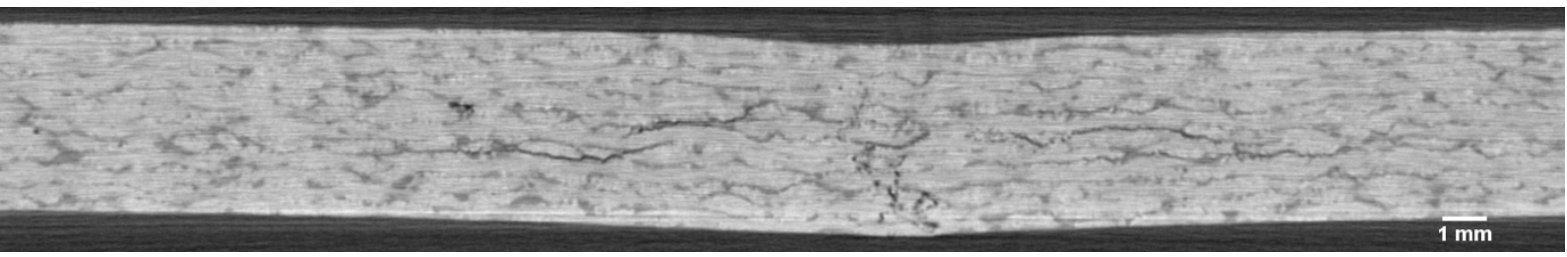

\section{J}

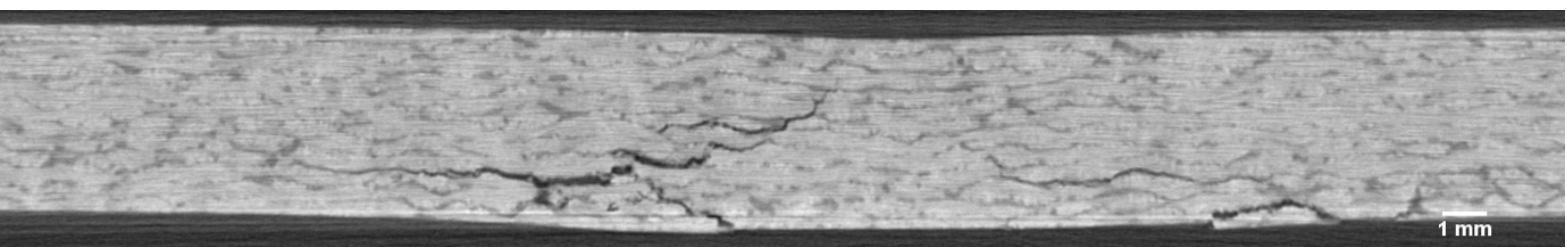


Figure 13

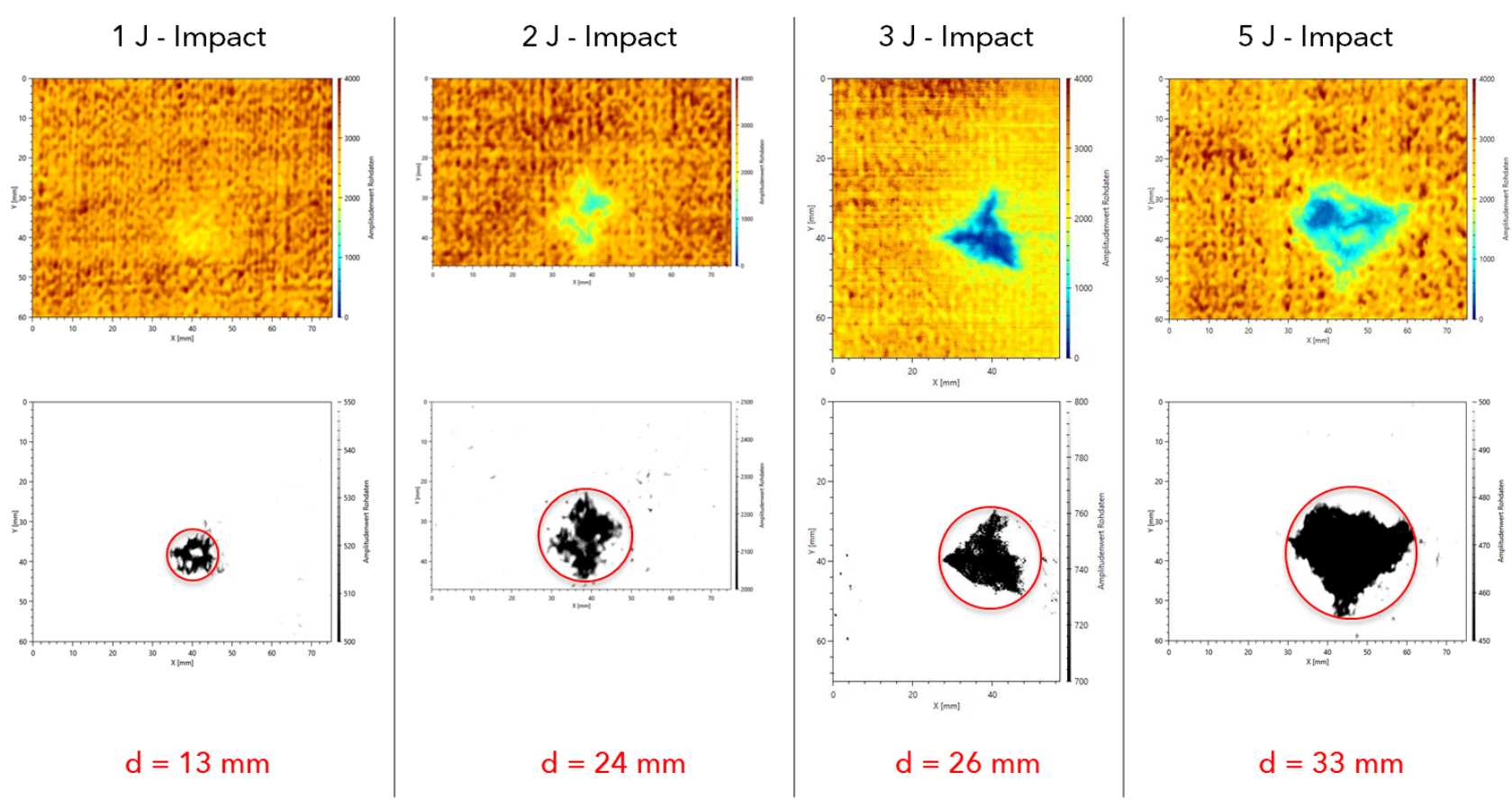

Figure 14

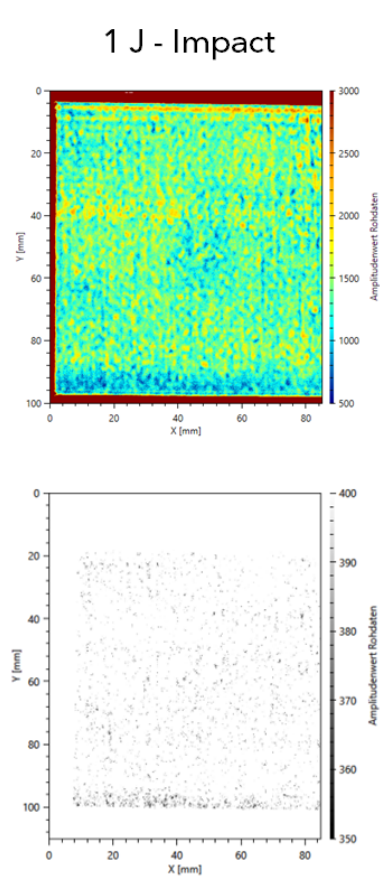

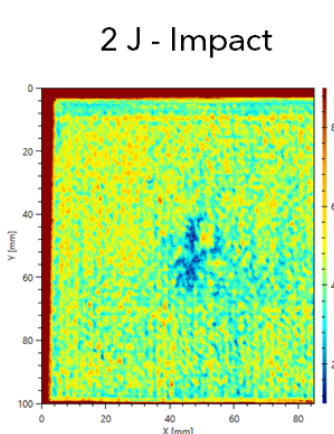

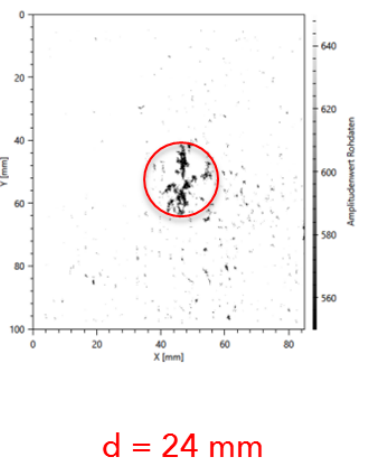

$3 \mathrm{~J}$ - Impact
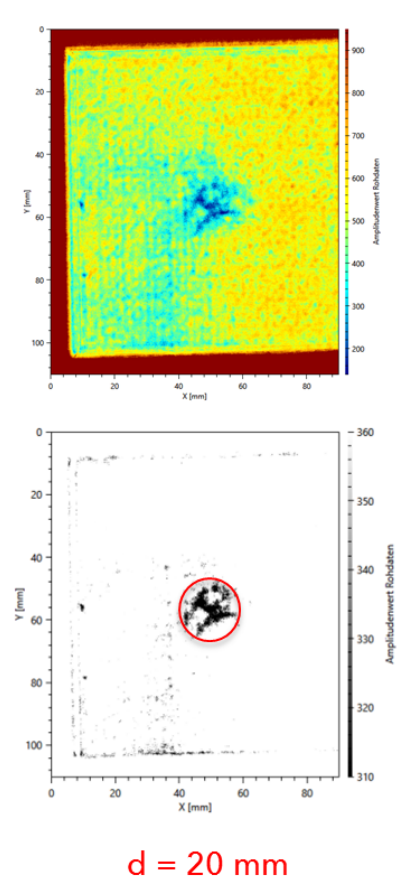

$5 \mathrm{~J}$ - Impact
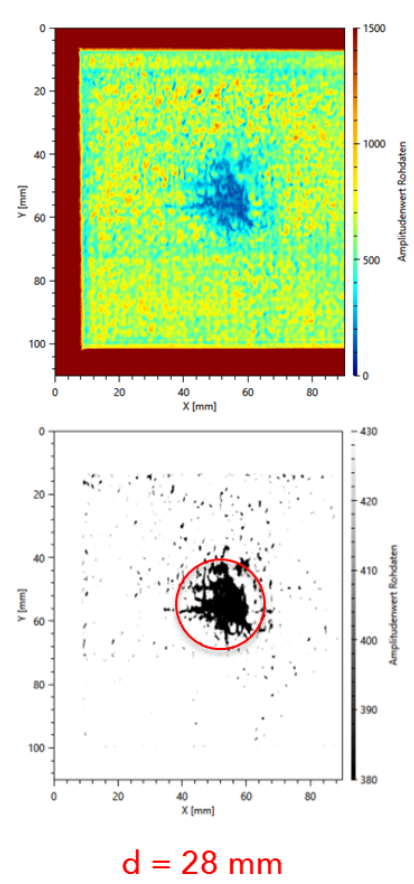